\title{
Determinant factors of tobacco use among ever-married men in Bangladesh
}

This article was published in the following Dove Press journal:

Drug, Healthcare and Patient Safety

13 May 2015

Number of times this article has been viewed

\author{
Md Shafiur Rahman ${ }^{1,2}$ \\ Md Nazrul Islam Mondal ${ }^{2}$ \\ Md Rafiqul Islam² \\ Md Mizanur Rahman² \\ M Nazrul Hoque 3 \\ Md Shamsher Alam ${ }^{4}$ \\ 'Department of Public Health, First \\ Capital University of Bangladesh, \\ Chuadanga, Bangladesh; ${ }^{2}$ Department \\ of Population Science and Human \\ Resource Development, University of \\ Rajshahi, Rajshahi, Bangladesh; ${ }^{3}$ Hobby \\ Center for Public Policy, University of \\ Houston, Houston, TX, USA; ${ }^{4}$ Faculty \\ of Ecology, Peoples' Friendship \\ University of Russia, Moscow, Russia
}

Correspondence: Md Nazrul Islam Mondal

Department of Population Science and Human Resource Development, University of Rajshahi, Rajshahi 6205, Bangladesh

Tel +880 72I 75I 217

Fax +880 721 750064

Email nazrulupm@gmail.com
Background: The burden of tobacco use is shifting from developed to developing countries. This study aimed to explore the different types of tobacco use, and to identify the determinant factors associated with the tobacco use among ever-married men in Bangladesh.

Data and methods: Data of 3,771 ever-married men, 15-54 years of age were extracted from the Bangladesh Demographic and Health Survey 2007. Prevalence rate, chi-square $\left(\chi^{2}\right)$ test, and binary logistic regression analysis were used as the statistical tools to analyze the data.

Results: Tobacco use through smoking (58.68\%) was found to be higher than that of chewing (21.63\%) among men, which was significantly more prevalent among the poorest, less educated, and businessmen. In bivariate analysis, all the socioeconomic factors were found significantly associated with tobacco use; while in multivariate analysis, age, education, wealth index, and occupation were identified as the significant predictors.

Conclusion: Tobacco use was found to be remarkably common among males in Bangladesh. The high prevalence of tobacco use suggests that there is an urgent need for developing intervention plans to address this major public health problem in Bangladesh.

Keywords: tobacco use, smoking tobacco, chewing tobacco, prevalence rate, logistic regression model

\section{Introduction}

Smoking tobacco is a risk factor for several diseases and has been increasing in many developing countries. It is not only a global public health concern, but also an economic problem amongst individuals, societies, and the country as a whole. Tobacco is a major avoidable cause of illness and premature death in low-income countries. ${ }^{1}$ The epidemic of tobacco use is shifting from developed to developing countries especially in People's Republic of China, India, Thailand, and Bangladesh. The risks of cancer, cardiovascular disease, respiratory disease, and a range of other health problems are increased in tobacco smokers and, as a consequence, smokers are more likely than nonsmokers to die prematurely. ${ }^{2}$ Smoking is considered a leading cause of morbidity and mortality in virtually every country in the world, and it is the second only to high blood pressure as a risk factor for global disease burden. ${ }^{3}$ Tobacco use causes more than 440,000 deaths in the US per year, accounting for one out of every five deaths. ${ }^{4}$ In addition, up to two-thirds of deaths in current smokers can be attributed to smoking. ${ }^{5}$ The higher prevalence of tobacco use in the developing countries are anticipated to result in large disease burden in the near future. ${ }^{6-8}$ Tobacco and poverty together form a vicious circle from which it is often difficult to escape. The adverse effects of tobacco use, including loss of income, being a leading causes of death, 
and contributing to chronic disease, are well documented worldwide. ${ }^{9}$ The prevalence of tobacco use is an important predictor of the future burden of tobacco-related diseases. ${ }^{10}$ It is estimated that each year tobacco smoking accounts for about $9 \%$ of deaths globally. ${ }^{11}$ Around $71 \%$ of lung cancer, $42 \%$ of chronic respiratory diseases, and nearly $10 \%$ of cardiovascular diseases are caused by smoking. It is reported that $18 \%$ of deaths in high-income countries have occurred due to tobacco use, whereas in middle- and low-income countries it is $11 \%$ and $4 \%$ respectively. ${ }^{12}$ In low- and middleincome countries such deaths are projected to increase from 3.4 to 6.8 million between 2002 and $2030 .{ }^{13}$ In addition, secondhand smoke exposure poses a serious risk of causing heart disease and various respiratory illness, lung cancer, etc among nonsmokers.

Both smoking and chewing tobacco products are commonly used in Bangladesh. The smokeless tobacco use constitutes a major part of overall tobacco use in Bangladesh and India. ${ }^{14}$ Smoking tobacco products include cigarettes, bidis (a small, thin, hand-rolled cigarette consisting of tobacco leaf, manufactured mostly in India and Bangladesh), hookah (a water pipe which is used to smoke tobacco through cooled water). Chewing or smokeless tobacco products include betel quid with tobacco (also known as pan, which is a mixture of betel leaf, areca nut, slaked lime, and tobacco), zarda (a mixture of tobacco, lime, spices, and vegetable dyes), zarda with areca nut, and gul (an oral tobacco powder that is rubbed over the gum and teeth). It is found that $28.30 \%$ men and $0.20 \%$ women in Bangladesh smoke cigarettes. In the Indian subcontinent, poor people use bidis as smoking tobacco. It has also been documented that the main predictors of cigarette smoking are sex, age, and having friends who smoke. ${ }^{15}$ Moreover, cigarette smoking is considered as a "gate way" toward illegal drug use, especially among adolescents. ${ }^{11}$

Various socioeconomic factors are found to be associated with different types of tobacco use. Studies regarding tobacco use in developing countries provided mixed results. ${ }^{6,8,10,13-21}$ No reliable study on tobacco use, including correlates of tobacco use, among men in Bangladesh has been completed at this time. Thus, it is an important task to identify the determining factors of tobacco use among the male population in Bangladesh. The specific objectives of this study are to explore different types of smoking and chewing tobacco use, and to identify the socioeconomic determinant factors among men in Bangladesh. Hopefully, this study will be very helpful in filling information gaps and suggesting possible future studies.

\section{Methods}

\section{Sources of data}

The study used a nationally representative set of crosssectional data extracted from the Bangladesh Demographic and Health Survey (BDHS) 2007. ${ }^{22}$ BDHS is a periodic survey conducted in Bangladesh to serve as a source of population and health data for policymakers, program managers, and the research community. The survey was conducted under the authority of the National Institute of Population Research and Training (NIPORT), Ministry of Health and Family Welfare (MOHFW), Bangladesh. The BDHS 2007 was the fifth national Demographic and Health Survey (DHS) conducted in Bangladesh. Previously, BDHS was conducted in 1993-1994, 1996-1997, 1999-2000, and 2003-2004. The sixth national BDHS has already been conducted in 2011-2012. However, in the latest survey, BDHS 2011 did not include data regarding tobacco use. BDHS 2007 was designed to produce representative results for the country as a whole, for urban and rural areas separately, and for each of the six administrative divisions of the country. All ever-married women 10-49 years of age and ever-married men 15-54 years of age who were the usual members of the selected households and those who spent the last night before the survey in the selected households were eligible to be interviewed in the survey. The details of the sampling survey design, survey instruments, and quality control are reported elsewhere. ${ }^{22}$ However, a brief description is provided in the following subsections.

\section{Sampling}

The sampling frame used for BDHS 2007 was the Population Census of the People's Republic of Bangladesh conducted in $2001,{ }^{23}$ provided by the Bangladesh Bureau of Statistics. The sampling frame comprised of 259,532 enumeration areas (EAs) created for the 2001 census. An EA is a geographic area consisting of a convenient number of dwelling units which served as counting unit for the census, with an average size of around 100 households. The survey contains locational information, type of residences, the number of residential households, and the number of males and females in the population. Administratively, Bangladesh was divided into six divisions (now seven divisions). Each division is in turn divided into zilas (districts); each zila into thanas (police stations); each thana into unions; each union into wards; and each ward into villages. An EA can include a group of small villages, or a village, or a part of a large village. These divisions allow the country as a whole to be easily separated into rural and urban areas. Urban areas were further classified into three groups; 1) statistical metropolitan areas, 2) municipality areas, and 3) other urban areas. In total, 
22 sampling strata were created. Samples were selected independently in each stratum, by a two stages of selection. In the first stage, 361 EAs (urban, 134; rural, 227) were selected with probability proportional to the EA size, and with independent selection in each sampling stratum with the sample allocation technique. In the second stage, household selection was equitably distributed with 30 households per EA. In order to minimize the task of household listing, the selected EAs with an estimated number of households greater than 300 were segmented. Only one segment was selected for the survey with probability proportional to the segment size. So, a BDHS 2007 data cluster is either an EA or a segment of an EA.

\section{Sample size selection}

About 10,819 households were selected, of which 10,461 were occupied. Interviews were successfully completed in 10,400 households ( $99.40 \%$ response rate). From every second household, a total of 4,074 eligible ever-married men were selected, of which $3,771(92.60 \%$ of the total sample) were successfully interviewed. The survey collected data on various demographic and health characteristics and also evaluated the effects of socioeconomic inequalities on smoking and chewing tobacco. This study has highlighted socioeconomic differences in smoking and chewing tobacco prevalence among 3,771 males in Bangladesh. However, due to missing information, four respondents were excluded from the chewing tobacco analysis. All questionnaires were pretested before data collection. After data collection, data processing was carried out using CSPro, including editing the inconsistencies observed in the computer program. To ensure the quality of the data, every stage of the survey was carefully monitored by the United States Agency for International Development, NIPORT, Mitra and Associates, MOHFW, and Macro International based in the USA. ${ }^{22}$

\section{Variables}

The unit of analysis for the study was tobacco use. To assess the determinants of tobacco use among ever-married men, two types of tobacco use viz, 1) smoking tobacco and 2) chewing tobacco were considered. The respondents answered in a dichotomous form as: 1) no and 2) yes. This study used six explanatory variables, with categories shown in parentheses: age in years $(<25,1 ; 25-39,2 ; \geq 40,3)$; place of residence (rural, 1; urban, 2;); education level (no education, 0 ; primary, 1; secondary, 2; higher, 3); wealth index (poorest, 1; poor, 2; middle income, 3; rich, 4; richest, 5); occupational status (unskilled worker, 1; semiskilled worker, 2; professional personnel, 3; businessmen, 4; unemployed, 5; agricultural worker, 6); and earned family income basic need (sufficient, 1; moderately sufficient, 2; insufficient, 3 ). The categories and coding systems of the variables were modeled on the previous study. ${ }^{24}$

\section{Statistical analysis}

Descriptive analysis was conducted to determine the distribution of subjects by socioeconomic characteristics. Prevalence rate $(\mathrm{PR})$, chi-square $\left(\chi^{2}\right)$ test, and binary logistic regression analysis were used as the statistical tools to analyze the data. A subject is defined as a smoker if he had smoked more than 100 cigarettes in his life time. ${ }^{25}$ Nonsmokers are those who did not smoke or smoked less than 100 cigarettes in their lifetime. But in BDHS 2007, men who smoked cigarettes or used other tobacco products in the preceding 24 hours were considered as the respondents. To calculate the PR of smoking (either cigarette or bidi) and chewing tobacco, the following formula is used: ${ }^{7}$

\section{Prevalence rate (PR)

$$
=\frac{\text { All cases of the factor of interest }}{\text { Total population at risk at a given time }} \times 100
$$

Bivariate analysis ( $\chi^{2}$ test) was used to assess differences in the prevalence of tobacco use by socioeconomic characteristics. It was applied to determine the association between independent and outcome variables. Effects of independent variables were also assessed after adjusting for other variables using binary logistic regression analysis. In this study, logistic regression analysis was mainly used to identify the important determinant factors of smoking (either cigarette or bidi) and chewing tobacco variables. The dependent variables considered in this study are classified as follows:

Model 1:

$$
Y=\left\{\begin{array}{l}
1, \text { if the respondent smokes tobacco } \\
\quad(\text { either cigarette or bidi) } \\
0, \text { otherwise }
\end{array}\right.
$$

Model 2:

$$
Y=\left\{\begin{array}{l}
1, \text { if the respondent chews tobacco } \\
0, \text { otherwise }
\end{array}\right.
$$

The Statistical Package for Social Sciences (SPSS) version 20 (IBM SPSS Inc., Chicago, IL, USA) was used for statistical analysis. 


\section{Results}

\section{Univariate analysis}

The background characteristics of the respondents are presented in Table 1. The results revealed that around half of the respondents (47.81\%) were aged 25-39 years and, $44.89 \%$ respondents were aged 40 years and above, a few $(7.30 \%)$ were less than aged 25 years. A higher percentage of respondents $(61.73 \%)$ were found in the rural areas. The wealth index indicates that a few (15.78\%) were poorest, $19.04 \%$ were poorer, $19.78 \%$ were middle income, and $25.80 \%$ were in the richest group. Around one-third (32.07\%) of the

Table I Background characteristics of ever-married men in Bangladesh ( $\mathrm{N}=3,77 \mathrm{I})$

\begin{tabular}{|c|c|c|}
\hline Characteristics & Number (n) & Percentage (\%) \\
\hline \multicolumn{3}{|l|}{ Age (years) } \\
\hline$<25$ & 275 & 7.30 \\
\hline $25-39$ & $\mathrm{I}, 803$ & 47.81 \\
\hline$\geq 40$ & 1,693 & 44.89 \\
\hline \multicolumn{3}{|l|}{ Residence } \\
\hline Urban & $\mathrm{I}, 443$ & 38.27 \\
\hline Rural & 2,328 & 61.73 \\
\hline \multicolumn{3}{|l|}{ Education level } \\
\hline Illiterate & $\mathrm{I}, 092$ & 28.96 \\
\hline Primary & 1,205 & 31.95 \\
\hline Secondary & 944 & 25.04 \\
\hline Higher & 530 & 14.05 \\
\hline \multicolumn{3}{|l|}{ Wealth index } \\
\hline Poorest & 595 & 15.78 \\
\hline Poor & 718 & 19.04 \\
\hline Middle income & 746 & 19.78 \\
\hline Rich & 739 & 19.60 \\
\hline Richest & 973 & 25.80 \\
\hline \multicolumn{3}{|l|}{ Occupational status } \\
\hline Agricultural worker & 1,210 & 32.07 \\
\hline Unskilled worker & 768 & 20.37 \\
\hline Semiskilled worker & 566 & 15.02 \\
\hline Professional personnel & 212 & 5.62 \\
\hline Businessmen & 908 & 24.08 \\
\hline Unemployed & 107 & 2.84 \\
\hline \multicolumn{3}{|l|}{ Earned family basic need } \\
\hline Sufficient & 449 & 12.22 \\
\hline Moderately sufficient & 2,218 & 60.39 \\
\hline Insufficient & 1,006 & 27.39 \\
\hline \multicolumn{3}{|l|}{ Smoking tobacco } \\
\hline Yes & 2,213 & 58.68 \\
\hline No & $\mathrm{I}, 558$ & 41.32 \\
\hline \multicolumn{3}{|l|}{ Chewing tobacco ${ }^{b}$} \\
\hline Yes & 815 & 21.64 \\
\hline No & 2,952 & 78.36 \\
\hline
\end{tabular}

Notes: Unskilled worker includes rickshaw pullers, brick breakers, construction workers, domestic servants, factory workers, blue collar workers, etc; semi-skilled worker includes carpenters, masons, bus/taxi drivers, etc; professional personnel include medical doctors, lawyers, actors, teachers, etc. 'Due to missing information, 98 respondents were excluded. 'Due to missing information, four respondents were excluded. respondents were agricultural workers, one-fifth (20.37\%) were unskilled workers (such as rickshaw pullers, brick breakers, construction workers, domestic servants, factory workers, blue collar workers, etc), 15.02\% respondents were semiskilled labors (carpenters, masons, bus/taxi drivers, etc), 5.62\% respondents were professional personnel (such as medical doctors, lawyers, actors, teachers, etc), $24.08 \%$ respondents were involved with different types of business, and the rest were unemployed. In regard to earnings, it was found that more than half of the respondents' $(60.38 \%)$ earnings were moderately sufficient for their family's basic needs, whereas $12.22 \%$ respondents' earning was sufficient, and the rest $(27.40 \%)$ was insufficient for their families' basic needs. A higher percentage of respondents (58.68\%) smoked tobacco, whereas only one-fifth of them (21.63\%) chewed tobacco.

\section{Bivariate analysis}

The results of the bivariate analysis ( $\chi^{2}$ test) and tobacco use PR are presented in Table 2. The study results disclose the prevalence of smoking and chewing tobacco by socioeconomic characteristics among males. Almost all of the factors were statistically significantly associated with smoking and chewing tobacco $(P<0.001)$. The results revealed that the overall PR of tobacco use through smoking was $58.68 \%$ and through chewing was $21.64 \%$. Thus, the PR for smoking tobacco was around three times higher than that of chewing tobacco among ever-married males. It was found that the PR of smoking tobacco gradually increased while that of chewing tobacco gradually decreased with increase in age. Tobacco use through smoking (60.91\%) and chewing (22.53\%) were more prevalent in the rural areas than in urban areas. The PR of both smoking tobacco and chewing tobacco gradually decreased as education levels increased, and income levels improved. By occupational status, the highest PRs (smoking tobacco, 64.71\%; chewing tobacco, $23.73 \%$ ) were found among unskilled workers. Finally, tobacco PRs (smoking tobacco, 64.12\%; chewing tobacco, $24.18 \%$ ) were found to be highest among males whose earned family basic needs were insufficient.

\section{Multivariate analysis}

The binary logistic regression models controlling for the confounding factors of respondents' age, place of residence, education level status, wealth index, occupational status, and earned family basic need were estimated to examine the association between tobacco use through smoking and chewing. The odds ratios (ORs) for tobacco use through smoking and chewing and estimated $95 \%$ confidence interval (CI) for these 
Table 2 Association and prevalence of tobacco use among ever-married men $(\mathrm{N}=3,77 \mathrm{I})$

\begin{tabular}{|c|c|c|c|c|c|c|c|c|}
\hline \multirow[t]{2}{*}{ Factors } & \multicolumn{4}{|c|}{ Smoking tobacco $(n)$} & \multicolumn{4}{|c|}{ Chewing tobacco $(n)^{b}$} \\
\hline & Yes & No & $P$-values & PR (\%) & Yes & No & $P$-values & PR (\%) \\
\hline \multicolumn{9}{|l|}{ Age (years) } \\
\hline$<25$ & 172 & 103 & $<0.001$ & 62.55 & 29 & 246 & $<0.00 \mathrm{I}$ & 10.55 \\
\hline $25-39$ & 999 & 804 & & 55.41 & 311 & $\mathrm{I}, 490$ & & 17.27 \\
\hline$\geq 40$ & 1,042 & 651 & & 61.55 & 475 & 1,216 & & 28.09 \\
\hline \multicolumn{9}{|l|}{ Place of residence } \\
\hline Urban & 795 & 648 & $<0.001$ & 55.09 & 291 & $\mathrm{I}, 150$ & $<0.05$ & 20.19 \\
\hline Rural & 1,418 & 910 & & 60.91 & 524 & $\mathrm{I}, 802$ & & 22.53 \\
\hline \multicolumn{9}{|l|}{ Education level } \\
\hline Illiterate & 781 & 311 & $<0.001$ & 71.52 & 271 & 820 & $<0.00 \mathrm{I}$ & 24.84 \\
\hline Primary & 739 & 466 & & 61.33 & 304 & 900 & & 25.25 \\
\hline Secondary & 503 & 441 & & 53.28 & $|7|$ & 772 & & 18.13 \\
\hline Higher & 188 & 342 & & 35.47 & 69 & 460 & & 13.04 \\
\hline \multicolumn{9}{|l|}{ Wealth index } \\
\hline Poorest & 413 & 182 & $<0.001$ & 69.41 & 158 & 436 & $<0.001$ & 26.60 \\
\hline Poor & 455 & 263 & & 63.37 & 182 & 535 & & 25.38 \\
\hline Middle income & 474 & 272 & & 64.54 & 180 & 566 & & 24.13 \\
\hline Rich & 411 & 328 & & 55.62 & 143 & 596 & & 19.35 \\
\hline Richest & 460 & 513 & & 47.28 & 152 & 819 & & 15.65 \\
\hline \multicolumn{9}{|l|}{ Occupational status } \\
\hline Agricultural worker & 756 & 454 & $<0.001$ & 62.48 & 284 & 926 & $<0.00 \mathrm{I}$ & 23.47 \\
\hline Unskilled worker & 497 & 271 & & 64.71 & 182 & 585 & & 23.73 \\
\hline Semiskilled worker & 314 & 252 & & 55.48 & 119 & 446 & & 21.06 \\
\hline Professional personnel & 59 & 153 & & 27.83 & 27 & 184 & & 12.80 \\
\hline Businessmen & 534 & 374 & & 58.81 & 186 & 721 & & 20.51 \\
\hline Unemployed & 53 & 54 & & 49.53 & 17 & 90 & & 15.89 \\
\hline \multicolumn{9}{|l|}{ Earned family basic need ${ }^{a}$} \\
\hline Sufficient & 226 & 223 & $<0.001$ & 50.33 & 80 & 369 & $<0.001$ & 17.82 \\
\hline Moderately sufficient & $|, 29|$ & 927 & & 58.21 & 477 & $\mathrm{I}, 738$ & & 21.53 \\
\hline Insufficient & 645 & 361 & & 64.12 & 243 & 762 & & 24.18 \\
\hline Total & 2,213 & 1,558 & & 58.68 & 815 & 2,952 & & 21.64 \\
\hline
\end{tabular}

Note: a Due to missing information, 98 respondents were excluded; ' $D$ ue to missing information, four respondents were excluded.

Abbreviation: PR, prevalence rate.

ORs are presented in Table 3. The OR provided an indication of the likelihood of tobacco use among males compared with the nontobacco users, while CI states the lower and upper bounds of OR. In binary logistic regression analysis, two models (Model 1 for smoking tobacco, and Model 2 for chewing tobacco) were fit. In Model 1, respondents' age, education level, wealth index, and occupational status were found to be statistically significant predictors. Again, in Model 2, respondents' age, education level, and wealth index were found to be statistically significant predictors.

In Model 1, males aged 25-39 years have less likelihood (OR: 0.81 ; 95\% CI: 0.703-0.937) of smoking tobacco compared to males 40 years and above. The risk of smoking tobacco was found comparatively higher in the younger ages ( $<25$ years) (OR: 1.05; 95\% CI: 0.800-1.390). The results revealed that respondents who were illiterate, primary educated, and secondary educated were 3.23 times (OR: 3.23; 95\% CI: 2.423-4.305), 2.15 times (OR: 2.15; 95\% CI: 2.423-4.305), and 1.65 times (OR: 1.65; 95\%
CI: 1.267-2.138), respectively, more likely to smoke when compared to higher educated respondents. The respondents in the poorest (OR: 1.53; 95\% CI: 1.152-2.021) and middle income (OR: 1.37; 95\% CI: 1.076-1.746) quintiles have significantly higher risk for smoking tobacco compared to the richest males. When considering occupational status, the respondents who were professional personnel were less likely to smoke tobacco (OR: 0.638; 95\% CI: 0.432-0.943) and businessmen were more likely to smoke tobacco (OR: 1.24; 95\% CI: 1.019-1.520) when compared to the respondents who were agricultural workers.

In Model 2, males aged less than 25 years (OR: 0.28; 95\% CI: 0.189-0.426) and aged 25-29 years (OR: 0.52; 95\% CI: 0.443-0.619) have less likelihood of chewing tobacco compared to males aged 40 years and above. The results revealed that respondents who were illiterate were 1.47 times (OR: 1.47; 95\% CI: 1.007-2.143) and primary educated were 1.70 times (OR: 1.70; 95\% CI: 1.184-2.451) more likely to chew tobacco when compared to higher educated respondents. 
Table 3 Effects of socioeconomic factors on smoking and chewing tobacco among ever-married men

\begin{tabular}{|c|c|c|c|c|}
\hline \multirow[t]{2}{*}{ Factors } & \multicolumn{2}{|c|}{ Smoking tobacco } & \multicolumn{2}{|c|}{ Chewing tobacco } \\
\hline & OR & $\begin{array}{l}95 \% \mathrm{Cl} \\
\text { of OR }\end{array}$ & OR & $\begin{array}{l}95 \% \mathrm{Cl} \\
\text { of OR }\end{array}$ \\
\hline \multicolumn{5}{|l|}{ Age (years) } \\
\hline$<25$ & 1.05 & $0.800-1.390$ & $0.28^{*}$ & $0.189-0.426$ \\
\hline $25-39$ & $0.8 I^{* *}$ & $0.703-0.937$ & $0.52^{*}$ & $0.443-0.619$ \\
\hline$\geq 40$ (RC) & 1.00 & & 1.00 & \\
\hline \multicolumn{5}{|l|}{ Place of residence } \\
\hline Rural & 1.07 & $0.904-1.267$ & 1.16 & $0.949-1.408$ \\
\hline Urban (RC) & 1.00 & & 1.00 & \\
\hline \multicolumn{5}{|l|}{ Education level } \\
\hline illiterate & $3.23^{*}$ & $2.423-4.305$ & $1.47^{* *}$ & $1.007-2.143$ \\
\hline Primary & $2.15^{*}$ & $|.64|-2.8 \mid 7$ & $1.70 * *$ & $|| 84-2.45 \mid$. \\
\hline Secondary & $1.65^{*}$ & $1.267-2.138$ & 1.26 & $0.877-1.810$ \\
\hline Higher (RC) & 1.00 & & 1.00 & \\
\hline \multicolumn{5}{|l|}{ Wealth index } \\
\hline Poorest & $1.53 * *$ & $1.152-2.02 \mid$ & $1.84^{*}$ & I.323-2.547 \\
\hline Poor & 1.22 & $0.948-1.579$ & $1.7 I^{*}$ & $1.255-2.317$ \\
\hline Middle income & $1.37 * *$ & $1.076-1.746$ & $1.65^{*}$ & $1.235-2.213$ \\
\hline Rich & 1.06 & $0.853-1.326$ & $1.26^{*}$ & $0.951-1.667$ \\
\hline Richest (RC) & 1.00 & & 1.00 & \\
\hline \multicolumn{5}{|l|}{ Occupational status } \\
\hline Unskilled worker & 1.01 & $0.899-1.342$ & 0.52 & $0.919-1.445$ \\
\hline Semiskilled worker & 1.04 & $0.834-1.305$ & 1.15 & $0.942-1.602$ \\
\hline Professional personnel & $0.638 * *$ & $0.432-0.943$ & 1.23 & $0.567-1.608$ \\
\hline Businessmen & $1.24 * *$ & $1.019-1.520$ & 0.95 & $0.864-1.377$ \\
\hline Unemployed & $0.22 * *$ & $0.054-0.879$ & 1.09 & $0.168-4.051$ \\
\hline $\begin{array}{l}\text { Agricultural } \\
\text { worker (RC) }\end{array}$ & 1.00 & & 1.00 & \\
\hline \multicolumn{5}{|l|}{ Earned family basic need } \\
\hline Moderately sufficient & 1.103 & $0.889-1.368$ & 1.04 & $0.795-1.368$ \\
\hline Insufficient & 1.23 & $0.968-1.570$ & 1.06 & $0.785-|.42|$ \\
\hline Sufficient (RC) & 1.00 & & 1.00 & \\
\hline
\end{tabular}

Notes: $* P<0.05 ; * * P<0.01$

Abbreviations: $\mathrm{RC}$, reference category; $\mathrm{OR}$, odds ratio; $\mathrm{Cl}$, confidence interval.

The wealth index indicates that the poorest respondents, poor respondents, middle income respondents, and rich respondents were 1.84 times (OR: 1.84, 95\% CI: 1.323-2.547), 1.71 times (OR: 1.71; 95\% CI: 1.255-2.317), (OR: 1.65; 95\% CI: $1.235-2.213$ ), and 1.26 times (OR: 1.26 ; 95\% CI: 0.951-1.667), respectively, more likely to chew tobacco when compared to the richest respondents.

\section{Discussion}

Tobacco use is considered to be a long-standing problem in Bangladesh. The study findings from both bivariate and multivariate analyses demonstrate that the prevalence of smoking and chewing tobacco varied significantly by education levels, wealth index, and occupational categories. Overall, in this study the PRs were found to be $58.68 \%$ for smoking tobacco and $21.64 \%$ for chewing tobacco, whereas in the past studies in Bangladesh, the smoking prevalence was between 33.40\% and $41.0 \%{ }^{26}$ and chewing tobacco prevalence was $20.60 \% .^{10}$ This study identified that tobacco use has increased recently. Moreover, in neighboring countries, the prevalence of chewing tobacco was $17 \%$ for Pakistan ${ }^{16}$ and $21 \%$ for India, ${ }^{17}$ which are very close to our findings. The results of previous studies concluded that tobacco PRs are gradually increasing over time. ${ }^{27-29}$ The findings of this study also support these results. Daily smokers consumed an average of five cigarettes a day in Bangladesh, about eleven cigarettes a day in Vietnam, about 17 cigarettes in the USA, about 16 cigarettes a day in People's Republic of China, and about two cigarettes a day in India. ${ }^{12}$ In the South Asian countries, men used tobacco in different forms. In the 1980s, chewing tobacco and smoking bidis were common in Bangladesh, but since then smokers have generally preferred cigarettes. According to the results of both bivariate and multivariate analyses, the prevalence of smoking and chewing tobacco were found to be significantly lower in the middle aged (25-39 years) male population as compared to the younger and older age group. Similar findings were reported by other studies, ${ }^{30}$ but some research has found the highest risk of smoking prevalence in the middle aged group. . $^{18,1931}$ The younger people were viewed as being more likely to smoke because of the influence of peer pressure, image, and rebellion. ${ }^{8}$ Higher smoking prevalence was observed among male population who were living in rural areas rather than urban areas, but no significant urban-rural difference was observed in the PRs of smoking and chewing tobacco after adjusting for sociodemographic variables, which was similar to the other study for Bangladesh. ${ }^{10}$

Education emerges as a relatively stronger predictor among the study's sociodemographic variables. Significant variation $(P<0.001)$ of smoking risk was observed across education levels. Compared to those with a higher education, respondents with no education have more than three times the odds of being a smoker, and those who completed primary have more than double the odds of being a smoker. The results revealed an inverse association between education and smoking. Although smoking rates generally increases with decreasing education level, the greatest differences were observed between those with a higher education and those with no education and primary education. The patterns and magnitudes of educational differences in smoking prevalence observed in this study were similar to those observed to other studies. ${ }^{15,16,19,20}$

One of the background characteristics used throughout this study is an index of household economic status. The wealth index used in this study was developed and tested in a large number of countries to measure inequalities in household income, use of health services, and health outcomes. ${ }^{32} \mathrm{It}$ 
is an indicator of the level of wealth that was consistent with expenditure and income measures. ${ }^{33}$ The wealth index was constructed from data on household assets, including ownership of durable goods and dwelling characteristics. To create the wealth index, each asset was assigned a weight (factor score) generated through principal component analysis, and the resulting asset scores were standardized in relation to a normal distribution with a mean of 0 and standard deviation of $1 .{ }^{34}$ The sample was then divided into quintiles from one (lowest) to five (highest). Wealth quintiles are used as a background variable in the study to assess demographic and health outcomes in relation to socioeconomic status. In this study, the significant higher likelihood of smoking and chewing tobacco were found among the poorest and middle-income groups, with the least likelihood among the "richest groups". The odds of smoking and chewing tobacco varied significantly within different occupational classes even after controlling socioeconomic characteristics. The risk of smoking cigarettes or bidis was found to be distinctly lower among those who were employed in professional jobs (like doctors, teachers, lawyers, etc) rather than other occupational categories. The findings that unskilled workers, semiskilled workers, and businessmen were more likely to smoke than professional persons might be related with their low socioeconomic status and deprivation, which also were reported in other the studies. ${ }^{18,19}$ A similar finding reported that among Pakistani and Chinese populations, occupational categories such as businessmen and laborers were positively associated with smoking. ${ }^{6,13}$

Tobacco-related diseases, consequences, and costs are enormous and affect the entire population in Bangladesh. Smoking is associated with coronary heart disease, stroke, ulcers, respiratory infections, lung cancer, bronchitis, emphysema, early menopause, and stillborn and premature children. ${ }^{35}$ College students who smoke have higher rates of respiratory infections and asthma as well as a higher incidence of bacterial meningitis, especially among freshman living in dorms. ${ }^{36}$ Mental health disorders have been strongly associated with smoking, especially among adolescents and young adults. Smoking has been associated with suicidal tendencies. Adolescent smokers are two times more likely to develop a major depressive disorder than adolescent nonsmokers. ${ }^{37}$ College students who smoke are more likely to participate in the risky behaviors that pose some of the greatest health threats to 18-24 year olds. ${ }^{38}$ Risky sexual behaviors can result in human immunodeficiency virus infection and reduce life expectancy. ${ }^{39-41}$
The first limitation of this study was that the data used for the analysis were for only ever-married men. This study did not include females and unmarried men. The second limitation is that, the present study identified the PRs and associations between smoking tobacco and chewing tobacco with some selected predictors, viz, respondents' age, place of residence, education level, wealth index, occupational status, and earned family basic need; and utilized binary logistic regression models. Further studies may be conducted taking into consideration more variables using more sophisticated statistical tools.

\section{Conclusion}

Smoking is now recognized as a major public health problem in the developing world. The findings in this study highlighted that persistent socioeconomic factors affect smoking and chewing tobacco use among ever-married men in Bangladesh. The prevalence of tobacco use was found to be significantly higher among those men who were younger, living in rural areas, illiterate and lower educated, unskilled, poorest, and insufficient earners. Initiation to smoking tends to occur at an early age, and the majority of the people smoking tobacco are under 25 years of age, while the prevalence of chewing tobacco increased among higher ages ( $>40$ years). Tobacco consumption was significantly and inversely related to education level. Males with lower education levels were more likely to consume tobacco. More research work is needed in this study area. This study strongly supports the urgent need for smoking and chewing tobacco prevention and cessation efforts through effective interventions to control tobacco use. More strategies such as involvement of religious leaders, health services providers, teachers, community leaders, and mass media can reduce tobacco use among men in Bangladesh. Local and national programs that draw on relevant knowledge from other countries, but are appropriate to Bangladesh, need to be developed to tackle this major epidemic.

\section{Acknowledgments}

The authors are enormously grateful to Mitra and Associates, NIPORT, MOHFW, Government of Bangladesh, and Macro International, USA, for giving permission to use their database. The authors are thankful to the Department of Population Science and Human Resource Development, University of Rajshahi, Bangladesh for granting support to complete this study. Thanks are also due to the editor and the referees for their comments and criticism, which lead to a greatly improved version of this paper. 


\section{Disclosure}

The authors received no financial support for the research, authorship, and/or publication of this article. The authors report no conflicts of interest in this work.

\section{References}

1. Esson KM, Leeder SR. Millennium Development Goals and Tobacco Control. An Opportunity for Global Partnership. Geneva, Switzerland: World Health Organization; 2004.

2. US Department of Health and Human Services. The Health Consequences of Smoking - 50 Years of Progress: A Report of the Surgeon General. Atlanta, GA: US Department of Health and Human Services; 2014.

3. Lim SS, Vos T, Flaxman A, et al. A comparative risk assessment of burden of disease and injury attributable to 67 risk factors and risk factor clusters in 21 regions, 1990-2010: a systematic analysis for the global burden of disease study 2010. Lancet. 2012;380:2224-2260.

4. Centers for Disease Control and Prevention. prevalence of current cigarette smoking among adults and change in prevalence of current and some day smoking - United States, 1996-2001. Morb Mortal Wkly Rep. 2003;52(14):303-307.

5. Banks E, Joshy G, Weber MF, et al. Tobacco smoking and all-cause mortality in a large Australian cohort study: findings from a mature epidemic with current low smoking prevalence. BMC Med. 2015; 13:38.

6. Ali S, Sathiakumar N, Delzell E. Prevalence and socio-demographic factors associated with tobacco smoking among adult males in rural Sindh, Pakistan. Southeast Asian J Trop Med Public Health. 2006;37(5): 1054-1060.

7. Bhalwar R, Vaidya R. Text Book of Public Health and Community Medicine. Geneva, Switzerland: Department of Community Medicine, Armed Forces Medical College, World Health Organization; 2009.

8. Bush J, White M, Kai J, et al. Understanding influences on smoking in Bangladeshi and Pakistani adults: community based, qualitative study. BMJ Primary Care. 2003;326:962.

9. Ezzati M, Lopez AD. Estimates of global mortality attributable to smoking in 2000. Lancet. 2003;362(9387):847-852.

10. Flora MS, Mascie-Taylor CGN, Rahman M. Gender and locality differences in tobacco prevalence among adult Bangladeshis. Tob Control. 2009;18(6):445-450.

11. Gilliland FD, Islam T, Berhane K, et al. Regular smoking and asthma incidence in adolescents. Am J Respir Crit Care Med. 2006;174(10): 1094-1100.

12. Giovino GA, Mirza SA, Samet JM, et al. Tobacco use in 3 billion individuals from 16 countries: an analysis of nationally representative cross-sectional household surveys. Lancet. 2012;380(9842): 668-679.

13. Hu T-w, Tsai Y-w. Cigarette consumption in rural China: survey results from 3 provinces. Am J Public Health. 2000;90(11):1785-1787.

14. Palipudi KM, Gupta PC, Sinha DN, et al. Social determinants of health and tobacco use in thirteen low and middle income countries: evidence from global adult tobacco survey. PLoS One. 2012;7(3):e33466.

15. Reda AA, Moges A, Yazew B, et al. Determinants of cigarette smoking among school adolescents in eastern Ethiopia: a cross-sectional study. Harm Reduct J. 2012;9:39.

16. Qidwai W, Saleheen D, Saleem S, et al. Are our people health conscious? Results of a patients survey in Karachi, Pakistan. J Ayub Med Col Abbottabad. 2003;15(1):10-13.

17. Subramanian SV, Nandy S, Kelly M, et al. Patterns and distribution of tobacco consumption in India: cross sectional multilevel evidence from the 1998-1999 national family health survey. BMJ Primary Care. 2004;328:801-806.

18. Khan MMH, Khan A, Kraemer A, et al. Prevalence and correlates of smoking among urban adult men in Bangladesh: slum versus non-slum comparison. BMC Public Health. 2009;9(1):149.
19. Rani M, Bonu S, Jha P, et al. Tobacco use in India: prevalence and predictors of smoking and chewing in a national cross sectional household survey. Tob Control. 2003;12(4):e4.

20. Khan M, Aklimunnessa K, Kabir M, et al. Tobacco consumption and its association with illicit drug use among men in Bangladesh. Addiction. 2006;101(8):1178-1186.

21. Kabir MA, Goh KL, Khan MM. Tobacco consumption and illegal drug use among Bangladeshi males: association and determinants. Am J Mens Health. 2013;7(2):128-137.

22. National Institute of Population Research and Training (NIPORT). Bangladesh Demographic and Health Survey 2007. NIPORT, Dhaka; Bangladesh. Macro International, Calverton, MD, 2009.

23. Bangladesh Bureau of Statistics (BBS). Population Census-2001. Dhaka, Bangladesh: BBS, Planning Division, Ministry of Planning; 2003.

24. Mondal MNI, Hoque N, Chowdhury MRK, et al. Factors associated with misconceptions about HIV transmission among ever-married women in Bangladesh. Jpn J Infect Dis. 2015;68:13-19.

25. World Health Organization. Guidelines for Controlling and Monitoring the Tobacco Epidemic. Geneva, Switzerland: WHO; 1997.

26. Zaman MM, Choudhury SR, Ahmed J, et al. Non-biochemical risk factors for cardiovascular disease in general clinic-based rural population of Bangladesh. J Epidemiol. 2004;14(2):63-68.

27. World Health Organization (WHO). Global Adult Tobacco Survey: Bangladesh Report. Dhaka, Bangladesh: WHO Country Office for Bangladesh; 2009.

28. International Institute for Population Sciences (IIPS). Ministry of Health and Family Welfare, Government of India (2009-2010) Global Adult Tobacco Survey India (GATS India), India: IIPS; 2009-2010.

29. GATS China. Global Adult Tobacco Survey: China [Country Report]. 2010. Available from: http://www.who.int/tobacco/surveillance/en_tfi_ china_gats_factsheet_2010.pdf?ua=1. Accessed April 16, 2015.

30. Shah SM, Arif AA, Delclos GL, et al. Prevalence and correlates of smoking on the roof of the world. Tob Control. 2001;10(1):e1.

31. Nejjari C, Benjelloun MC, Berraho M, et al. Prevalence and demographic factors of smoking in Morocco. Int J Public Health. 2009; 54(6):447-451.

32. Rutstein S, Johnson K, Gwatkin D. Poverty, health inequality, and its health and demographic effects. Paper presented at: Annual Meeting of the Population Association of America; 2000; Los Angeles, CA.

33. Rutstein S. Wealth versus Expenditure: Comparison between the DHS Wealth Index and Household Expenditures in Four Departments of Guatemala. Calverton, MD: ORC Macro; 1999.

34. Gwatkin DR, Rutstein S, Johnson, K, et al; HNP/Poverty Thematic Group of The World Bank. Socio-economic Differences in Health, Nutrition and Poverty. Washington, DC: The World Bank; 2000.

35. National Institute on Drug Abuse. Smoking May Lead to Anxiety Disorders in Adolescents and Young Adults. Bethesda, MD: NIDA, 2001;16:1.

36. Halperin AC, Eytan TA. Tobacco Use Trends and Associated Risks in a University Population. Seattle, WA: Society for Research on Nicotine and Tobacco; 2001:23.

37. Brown R, Lewinson P, Seeley J, et al. Cigarette smoking, major depression, and other psychiatric disorders among adolescents. J Am Acad Child Adolesc Psychiatry. 1996;35(12):1602-1610.

38. Anthony J, Echegaray-Wagner F. Epidemiologic analysis of alcohol and tobacco use: patterns of co-occurring consumptions and dependence in the United States. Alcohol Res. Health. 2000; 24(4):201-208.

39. Mondal MNI, Shitan M. Relative importance of demographic, socioeconomic and health factors on life expectancy in low- and lower-middleincome countries. J Epidemiol. 2014;24(2):117-124.

40. Mondal MNI, Shitan M. Factors affecting the HIV/AIDS epidemic: an ecological analysis of global data. Afr Health Sci. 2013;13(2): 301-310.

41. Mondal MNI, Shitan M. Impact of socio-health factors on life expectancy in the low and lower middle income countries. Iranian J Public Health. 2013;42(12):1354-1362. 
Drug, Healthcare and Patient Safety

Dovepress

\section{Publish your work in this journal}

Drug, Healthcare and Patient Safety is an international, peer-reviewed open-access journal exploring patient safety issues in the healthcare continuum from diagnostic and screening interventions through to treatment, drug therapy and surgery. The journal is characterized by the rapid reporting of reviews, original research, clinical, epidemiological and

post-marketing surveillance studies, risk management, health literacy and educational programs across all areas of healthcare delivery. The manuscript management system is completely online and includes a very quick and fair peer-review system. Visit http://www.dovepress.com/ testimonials.php to read real quotes from published authors.

Submit your manuscript here: http://www.dovepress.com/drug-healthcare-and-patient-safety-journal 